\title{
Using a Mobile Phone and a Geobrowser to Create Multisensory Geographic Information
}

\section{Maria João Silva}

Instituto Politécnico do Porto,

Escola Superior de Educação

Rua Dr. Roberto Frias,

4200-465 Porto Portugal

mjosilva@yahoo.com

\section{Bruno Pestana}

Instituto Politécnico de Viseu,

Escola Superior de Educação

R. Maximiano Aragão,

3504-501 Viseu, Portugal

bpestana@esev.ipv.pt

João Correia Lopes

Universidade do Porto, INESC

Porto

Rua Dr. Roberto Frias,

4200-465 Porto, Portugal

jlopes@fe.up.pt

Copyright is held by the author/owner(s).

\begin{abstract}
This document describes how we are using mobile phones together with Google Earth to allow children to create multisensory geographic information in learning and participatory contexts.
\end{abstract}

\section{Keywords}

Multisensory, mobile learning, geographic information, environmental education, user interfaces

\section{ACM Classification Keywords}

K.3.1: Computers and Education: Computer Uses in Education. H.5.2. Information interfaces and presentation: Uses in Education.

\section{Introduction}

Multisensory geographic information is acquired by various human senses in embodied situated experiences [9]. This information is linked to specific locations and explicitly integrates cognitive, emotional, and physical experiences.

In order to improve environmental education in elementary schools, the Schoolsenses@Internet project has been inviting children to collaboratively create 
georeferenced multisensory information [9]. This project aims to allow children and teachers to create messages using a multisensory message editor or a mobile phone. Furthermore, the project evaluated Google Earth (GE) [6] as an engaging and useful tool to support the browsing of geographic information and the publishing of situated multisensory messages by elementary school children and teachers [4].

The present poster describes how, in the context of participatory design and evaluation workshops, children aged 8-11 used mobile phones to create georeferenced multisensory messages that are automatically displayed in GE which is embedded in a webpage. Moreover, this poster explains how GE was used as a tool enabling children to create and manipulate local multisensory environments in global contexts.

\section{Related Work}

In elementary schools, children can create geographic information. The Domesday [2] and the Globe projects [5] are pioneer examples that illustrate how such creation can improve learning. During the last few years, mobile devices, such as smart phones and PDAs, have been used in diverse research projects to support children in the creation of geographic information [1] [10] [12]. However, in these projects children were only invited to acquire and georeference visual and aural information.

Although not developed for children, it is worthwhile to mention the "Gawker's New York City Subway Smell Map" project which uses Google Maps [7] and icons to display smells encountered throughout New York's subway stations by citizens [3]. Smells, as well as tactile sensations, can also be described by text and image annotation [11].

In the Senses@Watch project, multisensory messages were created by citizens to report environmental situated problems in a collaborative website [11].The multisensory messages included photos, sounds, graphics and short textual descriptions and were Multimedia Messaging System (MMS) compatible [11]. MMS messages have been used in public participation projects [8] and displayed with Google Maps or similar tools. Nevertheless, we couldn't find examples of the use of georeferenced multisensory MMS to improve children's environmental educational activities.

\section{Allowing children to collaboratively create georeferenced multisensory information}

In order to allow children to create georeferenced multisensory messages in collaborative school activities we designed and prototyped a system that joins together Mobile Phones and GE.

The design process

We developed three participatory design and evaluation workshops with school children aged 8-11. In the first workshop we assessed the use of a specific GPS equipped mobile phone. Two other workshops were developed to explore the way children use the prototyped system. These workshops will be described after a brief presentation of the system prototype.

In the first workshop 10 girls and 10 boys successfully used the MIO A701 mobile phone to send georeferenced multisensory messages in the context of a storytelling activity on climate change. By observing how children used the mobile phone it was possible to 
configure its interface for an easier use; a shortcut key was consequently set to MMS editor. Furthermore, the virtual keyboard was configured to display larger letters. This workshop also informed us about what prerecorded sounds to include in the mobile phone.

\section{The system prototype}

The system prototype includes 1 ) a service to collect the messages created with mobile phone MIO A701; 2) an interface to GE - embedded in a project webpage to display those messages.

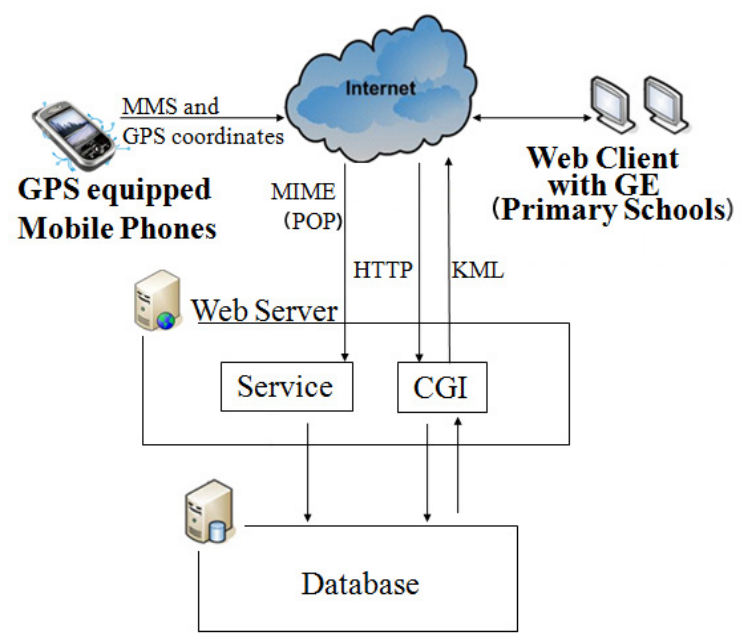

Figure 1: System architecture

The MMS message and GPS coordinates are sent to an email account. Afterwards, a service fetches the MIME encoded content and processes it in order to store all its parts (text, image, sound) in the project database (figure 1). Using $\mathrm{KML}$, the multimedia messages are sent from the project database to GE, which is embedded in a project webpage. For that to work, the multimedia information stored in the database is queried, using a network link and a CGI interaction with the server. Thus, children can access their own messages as well as messages sent by other children, using the GE standard interaction.

\section{Exploring how children create local multisensory environments in global contexts}

In the two other workshops, when invited to use GPS equipped mobile phones to create a "Senses at School" game in GE, children enthusiastically and successfully:

- Created georeferenced messages with diverse multisensory content (from garbage smells and sounds of toilet flushes to images and sounds of children playing soccer). They sent those messages to the collaborative project website (figure 2).

- Used GE as a publishing and browsing tool. The georeferenced multisensory MMS sent by children were automatically displayed in GE. Additionally, children were engaged in exploring their messages as well as other similar messages while travelling in GE (figure 3).

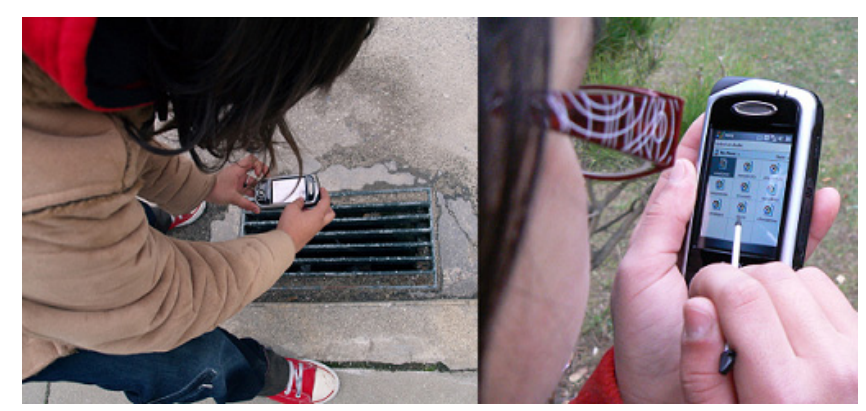

Figure 2: a) and b) A child composing a message that reports a run-off problem 


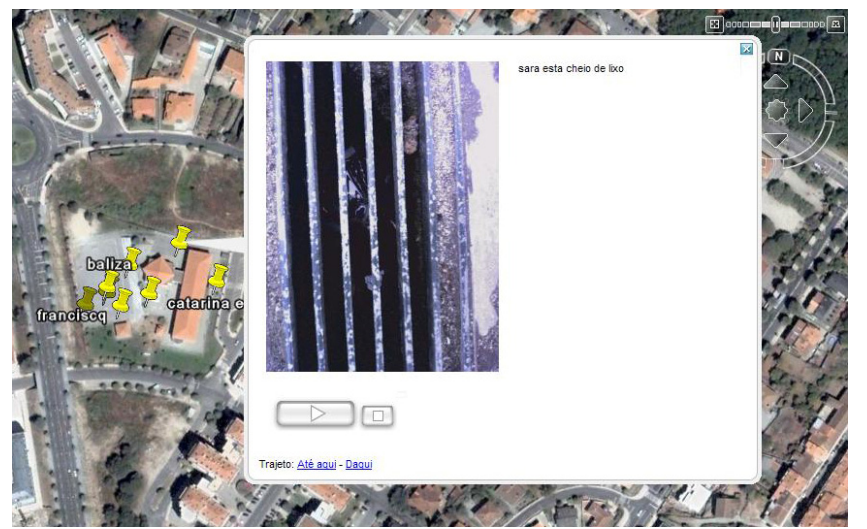

Figure 3: An MMS message displayed in GE

\section{Conclusion and future work}

During the workshops children used their senses to learn while exploring the environment. Furthermore, they used everyday ICT tools to communicate and share local environments in global contexts. Mobile phones and GE enabled children to become multisensory geographic information creators. Moreover the use of such tools allowed school children to create and publish contents portraying their own visions and suggestions.

In future work we will further explore how the affordances of those tools, together with a multisensory message editor and a multisensory simulation tool developed by the SchoolSenses@Internet research team, can empower children to become actors in real public participation processes.

\section{Acknowledgements}

We thank all the children and adults who took part in the Schoolsenses@Internet activities.
This research was partially funded by POSC/EIA/56954/2004.

\section{References}

[1] Bouvin, N. O., Brodersen, C., Hansen, F. A. Iversen, O. S., Nørregaard, P.. Tools of

contextualization: Extending the classroom to the field. In Proc. IDC '05, ACM Press (2005), 24-31.

[2] Domesday Project.

http://www.domesday1986.com/.

[3] Gawker's New York City Subway Smell Map. http://gawker.com/maps/smell.

[4] Gomes, M., Marcelino, M., Lima, F. and Silva, M. J."A Learning Evaluation Framework to Support the Schoolsenses@Internet Project". Proc. WBED' 07, ACTA Press (2007), 421-426.

[5] The Globe program. http://www.globe.gov/.

[6] Google Earth. http://earth.google.com/.

[7] Google Maps. http://maps.google.com/.

[8] Love Lewisham. http://www.lovelewisham.org/.

[9] Marcelino, M. J., Gomes, C. A., Silva, M. J. Gouveia, C., Fonseca, A., Pestana, B., \& Brigas C.. SchoolSenses@Internet: Children as Multisensory Geographic Creators. In Fernández Manjon, B. et al.

(eds.). Computers and Education: E-learning from theory to practice. Springer Netherlands (2007), 57-66. [10] Ohashi, Y., \& Arisawa, M. Nature Talk: A Proposed Audible Database System for Environmental Learning. Proc. IDC '06, ACM Press (2006), 167-168.

[11] Silva, M. J., Hipolito, J., \& Gouveia C.. Messages for environmental collaborative monitoring: The development of a multi-sensory Clipart. In Proc. INTERACT'03, IOS Press (2003), 896-899.

[12] Williams, M., Jones, O., Fleuriot, C., Wood, L., Children and emerging wireless technologies: Investigating the potential for spatial practice. In Proc. of $\mathrm{CHI}^{\prime} 05$, ACM Press (2005), 819-828. 